\title{
Correction to: Tanner-Whitehouse Skeletal Ages in Male Youth Soccer Players: TW2 or TW3?
}

\author{
Robert M. Malina ${ }^{1,11}$ (D) - Manuel J. Coelho-e-Silva ${ }^{2}$ - António J. Figueiredo ${ }^{2}$. \\ Renaat M. Philippaerts ${ }^{3}$ - Norikazu Hirose ${ }^{4} \cdot$ Maria Eugenia Peña Reyes $^{5}$. \\ Giulio Gilli $^{6}$ - Andrea Benso ${ }^{7}$. Roel Vaeyens ${ }^{3,8} \cdot$ Dieter Deprez $^{3} \cdot$ Luiz G. A. Guglielmo9 ${ }^{9}$ \\ Rojapon Buranarugsa ${ }^{10}$
}

Published online: 21 November 2017

(C) Springer International Publishing AG, part of Springer Nature 2017

\section{Correction to: Sports Med https://doi.org/10.1007/s40279-017-0799-7}

An Online First version of this article was made available online at https://link.springer.com/article/10.1007\% 2Fs40279-017-0799-7 on 29 October 2017. Errors were subsequently identified in the article, and the following corrections should be noted:

The original article can be found online at https://doi.org/10.1007/ s40279-017-0799-7.

Robert M. Malina

rmalina@1skyconnect.net

Manuel J. Coelho-e-Silva

mjcesilva@hotmail.com

António J. Figueiredo

afigueiredo@fcdef.uc.pt

Renaat M. Philippaerts

renaat.philippaerts@telenet.be

Norikazu Hirose

toitsu_hirose@Waseda.jp

Maria Eugenia Peña Reyes

eugeniapere@prodigy.net.mx

Giulio Gilli

giulio.gilli2@gmail.com

Andrea Benso

andrea.benso@unito.it

Roel Vaeyens

roel.vaeyens@ugent.be

Dieter Deprez

dieter.deprez@gmail.com

Luiz G. A. Guglielmo

luizguilherme@cds.ufsc.br

Rojapon Buranarugsa

rojapon@hotmail.com

\section{Author listing:}

The name of the eleventh author, which previously read:

"Luiz F. Guglielmo"

should read:

"Luiz G. A. Guglielmo"
1 Department of Kinesiology and Health Education, University of Texas, Austin, TX, USA

2 CIDAF (uid/dtp/04213/2006), Faculty of Sport Science and Physical Education, University of Coimbra, Coimbra, Portugal

3 Club Brugge KV, Brugge, Belgium

4 Faculty of Sports Sciences, Waseda University, Saitama, Japan

5 Instituto Nacional de Antropologia e Historia, Mexico, DF, Mexico

6 Associazione Italiana di Auxologia, Torino, Italy

7 Endocrinology, Diabetology and Metabolic Unit, Department of Medical Sciences, University of Turin, Turin, Italy

8 Department of Movement and Sport Sciences, Ghent University, Ghent, Belgium

9 Physical Effort Laboratory (Sports Center), Federal University of Santa Catarina, Florianópolis, Brazil

10 Department of Physical Education, Faculty of Education, Khon Kaen University, Khon Kaen, Thailand

1110735 FM 2668, Bay City, TX 77414, USA 


\section{Author affiliation:}

The affiliation of the eleventh author, which previously read:

9. Human Performance Research Group, Center for Health and Sport Science, Santa Catarina State University (CEFID/UDESC), Florianópolis, Brazil should read:

9. Physical Effort Laboratory (Sports Center), Federal University of Santa Catarina, Florianópolis, Brazil 